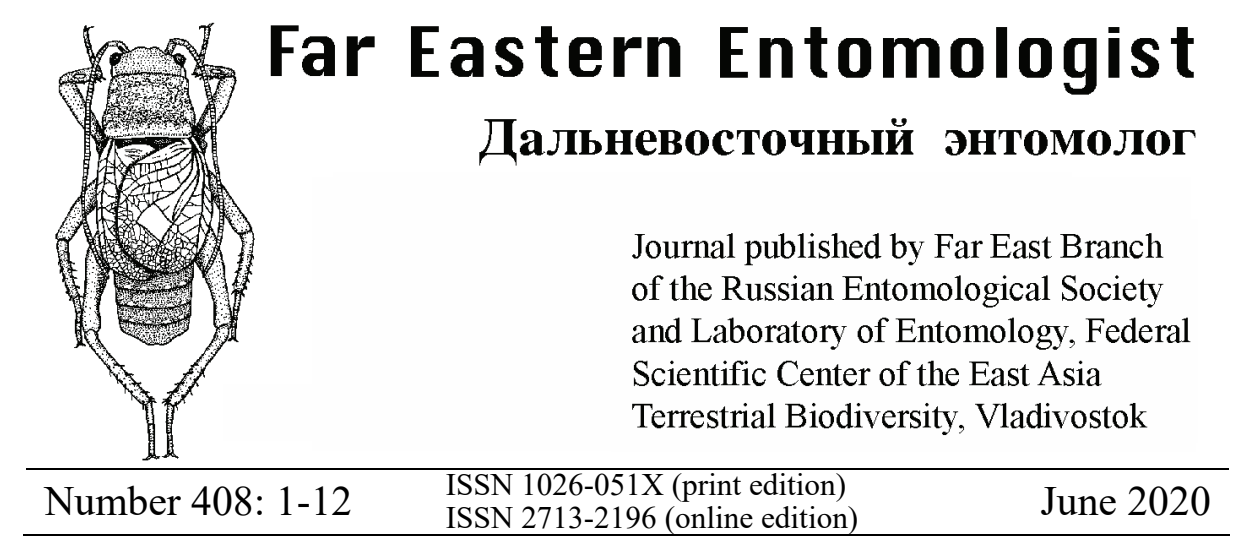

https://doi.org/10.25221/fee.408.1

http://zoobank.org/References/CF7B71E0-DEDD-4F93-972B-5143D12B1E38

\title{
DRACOMANTIS MIROFRATERNUS GEN. ET SP. N., A NEW GENUS AND SPECIES OF HIERODULINAE (MANTODEA: MANTIDAE) FROM VIETNAM
}

\section{E. O. Shcherbakov ${ }^{1 *}$, X. H. C. Vermeersch ${ }^{2)}$}

1) Department of Entomology, Faculty of Biology, Lomonosov Moscow State University, Leninskie Gory st. 1 bldg 12, Moscow 119991, Russia. *Corresponding author,E-mail:dracomantis@gmail.com

2) Department of Entomology, O.D. Phylogeny and Taxonomy, Royal Belgian Institute of Natural Sciences, Vautierstreet 29, Brussels B-1000, Belgium.

Summary. A new genus and species of praying mantis, Dracomantis mirofraternus gen et sp. n., is described from the Central Highlands of Vietnam. The new genus is provisionally placed in Hierodulinae (Mantidae) and readily diagnosed by a medium size, robust habitus, very thick metazonal keel and conspicuous reddish-black spot near the tibial spur groove on the forefemur.

Key words: Mantodea, new genus, new species, Greater Mekong region, SouthEast Asia.

Е. О. Щербаков, К. Х. К. Вермеерш. Dracomantis mirofraternus gen. et sp. n., новый род и вид Hierodulinae (Mantodea: Mantidae) из Вьетнама // Дальневосточный энтомолог. 2020. N 408. С. 1-12.

Резюме. Из Центрального плато, Вьетнам, описан новый род и вид богомолов, Dracomantis mirofraternus gen et sp. n. Новый род предварительно помещен в Mantidae: Hierodulinae и может быть легко идентифицирован по 
средней величине тела, коренастому габитусу, очень толстому метазональному килю и выделяющемуся красно-черному пятну вблизи когтевой ложбинки переднего бедра.

\section{INTRODUCTION}

Vietnam harbours a very rich but still poorly studied Mantodea fauna, with many new taxa that were only very recently discovered and described (Stiewe \& Shcherbakov, 2017; Shcherbakov, 2017; Schwarz et al., 2018; Vermeersch, 2018a, 2018b; Vermeersch et al., 2019). The description here presented of a new genus and species from the Vietnamese Central Highlands emphasises once again the huge gaps in our knowledge of extant Mantodea taxa.

\section{MATERIALS AND METHODS}

Dried specimens were softened in a water vapor camera and male genitalia were extracted by cutting the membrane connecting them to tergite $\mathrm{X}$ and coxosternite IX, after that the latter were extracted separately. Genitalia were macerated in $10 \%$ $\mathrm{KOH}$ water solution for several hours to clear them from muscles and fat, then washed in distilled water and in $96 \%$ ethanol. Prepared genitalia are stored in microvials with glycerin together with the specimens.

External morphology and male genitalia were studied using a Lomo-Eltem MBS10 (Moscow, Russia) binocular microscope and a Leica EZ4-W stereo-microscope (Brussels, Belgium). Photographs of the specimens were made with various Canon EOS digital cameras (Tokyo, Japan) and Sigma 105 mm F2.8 EX DG OS HSM Macro lenses (Kanagawa, Japan). Photos of the genitalia were made with Canon EOS 6D camera and Canon MP-E65mm F2.8 Macro lenses mounted on a macro setup. Serial photos were stacked in Zerene Stacker 1.04 (Zerene Systems LLC, Richland, WA, USA). All photos were processed in Adobe Photoshop CS5 software (Adobe Systems, San Jose, CA, USA).

The specimens used in this paper are deposited in the following collections:

ESPC - personal collection of Evgeny Shcherbakov, Ramenskoye;

MMUE - Manchester Museum, UK;

UniFI - University of Florence, Firenze;

ZIN -Zoological Institute of Russian Academy of Sciences, Saint-Petersburg.

Terminology follows Brannoch et al. (2017) and Schwarz \& Roy (2019) except that the measurements are taken after Shcherbakov (2017) and Vermeersch (2018). The distribution map was created in SimpleMappr (Shorthouse, 2010).

\section{DESCRIPTIONS OF NEW TAXA}

Order Mantodea Wood-Mason, 1889

Family Mantidae Latreille, 1802

Subfamily Hierodulinae Brunner de Wattenwyl, 1893 
Genus Dracomantis Shcherbakov et Vermeersch, gen. $\mathbf{n}$.

http://zoobank.org/NomenclaturalActs/FC48508B-CC4D-4CCB-87DB-25FC955E7B8B

Type species: Dracomantis mirofraternus Shcherbakov et Vermeersch, sp. n.

DIAGNOSIS. This new genus is provisionally placed in the subfamily Hierodulinae sensu Schwarz \& Roy (2019) based on the following characters. External habitus is very robust. Lower frons is typical for Hierodulinae, while the area between the base of the antenna and the complex eye possesses a tubercle, also present in several Hierodulinae genera. The afa is large and bulky, but lacks the wide separation between aafa and pafa diagnostical of Tenoderinae, Stagmomantinae and Vatinae.

It is readily distinguished from all other genera of the subfamily by a combination of the following characters: 1) robust habitus; 2) strong, thick metazonal keel, which makes metazone triangular in cross-section; 3) two distal processes with clearly separated bases; 4) afa without particularly strong sclerotization, spines or setae; 5) forefemoral spot. In habitus Dracomantis gen. nov. resembles some species of Hierodula Burmeister, 1838. Some Hierodula may also possess sdp with two apexes or a forefemoral maculation. None, however, have such a prominent metazonal keel. In species of Hierodula sensu lato with "double" sdp its two apexes are united by a common base, which is sclerotised dorsally by L4A-d. In contrast, the distal processes of Dracomantis gen. nov. do not share a common totally sclerotized base and the dorsal surface becomes sclerotized separately on each process. In addition, all Hierodula species with similar habitus are much larger than Dracomantis gen. nov. It is worth noting that Hierodula as currently conceived is a polyphyletic genus and will eventually be split into more natural genera.

Monotypic, therefore the genus characters are those of the type species.

ETYMOLOGY. The genus name is a combination of Latin draco (dragon), and the genus name Mantis, reflecting its robust and crenulated appearance.

\section{Dracomantis mirofraternus Shcherbakov et Vermeersch, sp. $\mathbf{n}$.}

http://zoobank.org/NomenclaturalActs/07079382-610A-4FEB-97E4-52BF459FBACD

Figs 1-9

TYPE MATERIAL. Holotype: male (Figs 1, 3, 5, 7, 9), Vietnam: Kon Tum prov., Kon Plong distr., Mang Canh vill., 30.III-2.IV 2005, S. Ryabov leg. (ZIN: ESZI001). Paratypes: 1 female (Figs 2, 4, 6, 8), Vietnam, Gia Lai - Kon Tum prov., $20 \mathrm{~km}$ N Buon Luoi vill., Tram Lap, 21.XI 1988, A.V. Gorochov leg. (ZIN: ESZI002); 1 male, Vietnam, Kon Tum prov., Kon Plong distr., 14 km N Kon Plong, $14^{\circ} 43^{\prime} 20^{\prime \prime} \mathrm{N}, 108^{\circ} 18^{\prime} 58^{\prime \prime} \mathrm{E}, 1030 \mathrm{~m}, 9-23 . \mathrm{IV}$ 2015, A.V. Abramov leg. (MMUE: F3459.23); 1 male, same data (MMUE: F3459.24); 2 males, Vietnam, Gia Lai prov., Kon Chu Rang Nature Reserve, ca. $8 \mathrm{~km}$ from HQ, 14³0.256' N, $108^{\circ} 30.109^{\prime}$ E, $1100 \mathrm{~m}, 8-12 . \mathrm{V}$ 2016, at light, L. Bartolozzi, A. Bandinelli, S. Bambi, V. Sbordoni leg. (UniFI: $n^{\circ}$ Mag. 3078 \#1\&2); 1 male, Vietnam, Gia Lai 


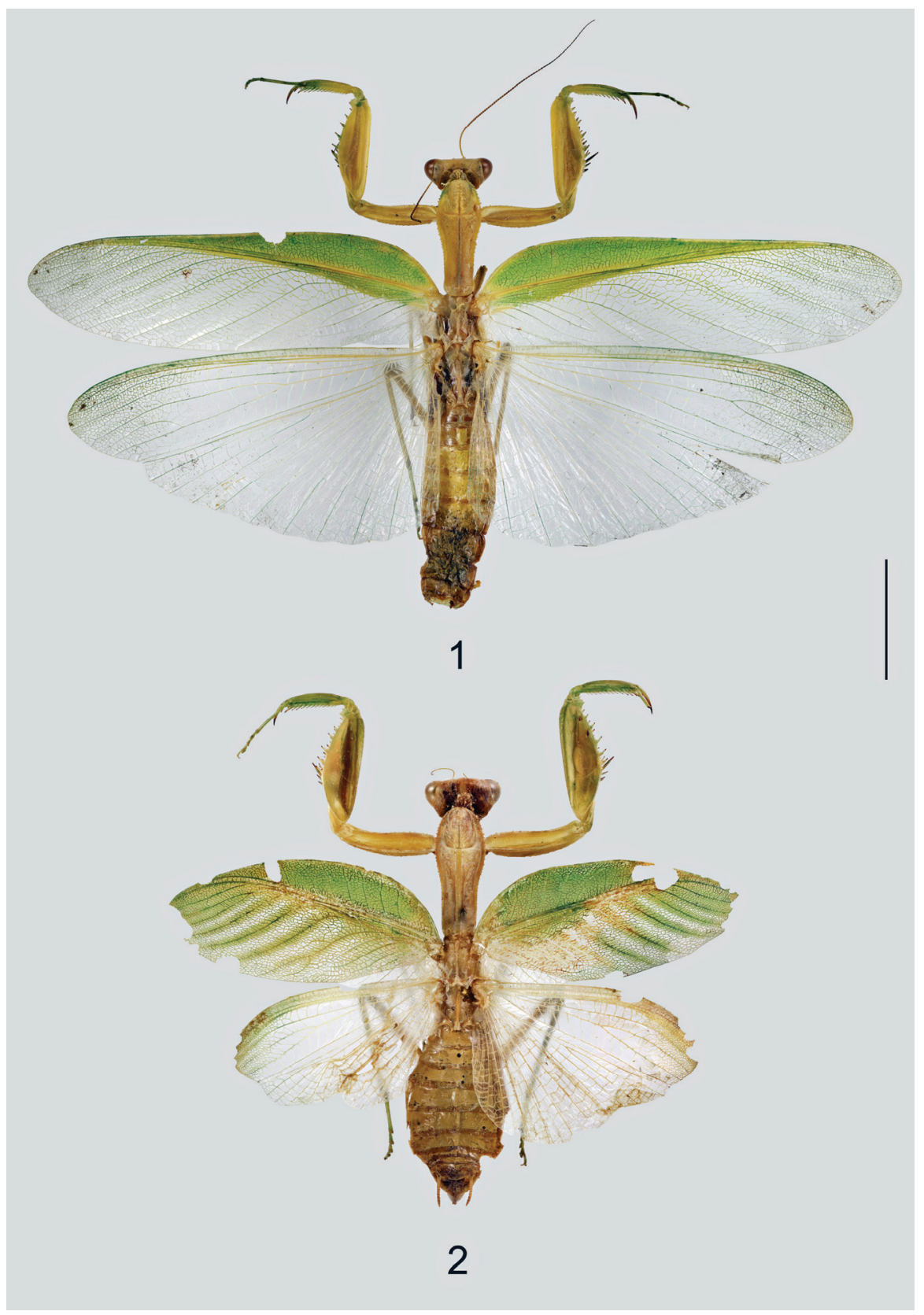

Figs 1-2. Dracomantis mirofraternus gen. et sp. n., habitus. 1 - holotype male; 2 paratype female. Scale $10 \mathrm{~mm}$. 
prov., Kon Chu Rang Nature Reserve, ca. 15 km from HQ, 14²31.212' N, 108 $28.192^{\prime}$ E, $1100 \mathrm{~m}$ asl, 8-12.V 2016, at light, L. Bartolozzi, A. Bandinelli, S. Bambi, V. Sbordoni leg. (UniFI: ${ }^{\circ}$ Mag. 3078 \#3); 1 male, Vietnam, Kon Tum prov., ca. 30 $\mathrm{km}$ from Kon Plong, $1250 \mathrm{~m}, 4-7 . \mathrm{V}$ 2016, at light, L. Bartolozzi, S. Bambi, A. Bandinelli, V. Sbordoni leg. (UniFI: $\mathrm{n}^{\circ}$ Mag. 3078 \#4, genital preparation Xavier Vermeersch GEN1836); 2 males, Vietnam, Quang Nam prov., Tay Giang distr., Axan Mt., 1300 m, III 2018, local collector leg. (ESPC0012 \& ESPC0013).

DESCRIPTION. Male (Fig. 1). Medium sized (body length 37-49 mm).

Head (Fig. 3) hypognathous, triangular, 1.4 times wider than high, about 1.5 times wider than supracoxal dilatation. Clypeus trapezoidal, its dorsal third with transverse, obtuse, low carina, ventral angles elevated while areas between angles and carina depressed. Thin longitudinal medial carina runs from angle of $\mathrm{V}$-shaped transverse carina onto labrum. Lower frons pentagonal, about 1.4 times wider than high, its ventral margin straight except lateral angles slightly protruding ventrad, lateral margins parallel and dorsal margin very obtuse. Lateral and dorsal margins with uninterrupted low to medium elevated carina. Lower frons surface mostly flat, with two feeble paramedian carinae interrupted in the middle. Ocelli roundedtriangular, form an angle of about $110^{\circ}$. Vertex straight, levelled with eyes, with two pairs of feeble sulci: one pair runs from lateral ocelli to complex eyes, then along eyes (frontal and parietal sulci), second pair runs posteriad lateral ocelli with two slight depressions at bases, being sometimes indistinct. Antennae filiform, more than 1.5 times longer than pronotum. Between base of antennae and eye small, but sharp tubercle. Juxta-ocular areas almost completely flat, posterior line of the head very weakly concave, slightly beyond eye line.

Pronotum (Fig. 7) robust, 2.5-2.7 times longer than its maximum width, triangular in cross-section, with widely rounded anterior and rounded-truncated posterior edges. Supracoxal dilatation weakly to moderately defined. Edges covered with separated small, rough, rounded tubercles, especially near supracoxal dilatation; anterior edge and posterior third of metazona with smooth edges. Dorsal surface of prozona with deep medial groove, not reaching anterior edge, with edges of the groove covered by rough tubercles. Metazona 2.0-2.4 times longer than prozona, with little to no constriction past the dilatation and narrow but noticeable lateral expansion along the edges. Dorsal surface of metazona with very strong, thick, elevated medial keel, not reaching posterior edge, covered along its length by separated tubercles. Dorsal surface of pronotum covered by rare tubercles in prozona and in the first half of metazona on the sides; tubercles along prozonal groove stouter than rest; surface along metazonal keel and in the posterior half of metazona without tubercles. Cervicalia complete; anterior and posterior ventral cervical sclerites very similar in size and shape; intercervical sclerites narrow, with deep groove along their middle, loosely connected with each other; postcervical plate very short, medially about as long as 1.5 times the maximum width of intercervical sclerites, laterally about the length of one intercervical sclerite, saddleshaped, medially with very elevated, thickened anterior edge, otherwise smooth. Furcasternite straight, with medial carina terminating at the end of posteriormost third of furcasternite, and two lower, shorter carinae laterad of medial one, not reaching posterior half of furcasternite and ending in paired bean-shaped feeble depressions. 
Cyclopic ear of DK type. Mesosternite with a pair of elevated, rounded tubercles.

Forelegs. Forecoxa roughly trapezoidal in cross-section, with dorsal, anterodorsal, ventral and posterior edges. Basal two thirds of the dorsal edge with spaced slanted sharp tubercles; size and number of tubercles varies greatly, with one specimen having tubercles so small that the edge almost smooth. Distal third of the dorsal edge always smooth. Dorsal and anterodorsal edge each with a row of tubercles. Ventral edge with about several dozens of tubercles, arranged more or less in two rows, larger ones similar to the largest tubercles of the dorsal edge in size. Posterior edge with about 20 significantly smaller tubercles, gradually decreasing in size distally. On all edges, tubercles most pronounced in basal two thirds, on distal third becoming much smaller or absent altogether. Size and number of tubercles vary greatly, with one specimen having tubercles so small that the dorsal edge almost smooth. All tubercles share the same shape, being small, slanted and with sharp apex. At the basis of each tubercle a single seta; setae at the bases of anterodorsal tubercles 2-4 times longer than the rest. Anterior apical lobes parallel. Forefemur (Fig. 5) moderately elongated, stout, with very well defined dorsal and posteroventral edges. Dorsal edge lamellar, straight, smooth to covered with very small tubercles making it crenulated, especially in distalmost part. Tibial spur groove at the end of basal third. Forefemur armed with 14-15 anteroventral spines, 4 discoidal and 4 to 5 posteroventral spines. Basal 12 anteroventral spines of alternating length, starting with a smaller spine, with larger spines being only a little larger than smaller spines, but sitting on higher sockets; this basal row followed by 1-2 spines slightly smaller than the smaller spines of the basal row, and finally by ultimate, larger spine. Discoidal spines length as follows: the second a little longer than the first, the third twice the second, the fourth almost as the second. Posteroventral spines length: the second a little longer than the first, the third and fourth (if present) as the second, the last (fifth or fourth) the smallest and widest. First and second posteroventral spines situated a little closer to each other than the rest. Genicular lobes prominent, with very short genicular spines present either on posterior or on both lobes of the femur. Anterior half of ventral surface distad of discoidal spines with very feeble tubercles, numerous in proximal half of this area, but very rare and displaced towards anteroventral spines in distal half, each tubercle with a long seta; posterior half with feeble round depression immediately near fourth discoidal spine to accommodate ultimate posteroventral spine of foretibia, as well as with a row of very small, almost flat tubercles running along posteroventral edge adjacent to posteroventral spines. Row of 7-9 very feeble tubercles stretches from second discoidal spine to trochanter-femur connection. Foretibia armed with 11-15 anteroventral spines, elongating distally, and 12-16 posteroventral spines (not counting tibial spur), also elongating distally. Anteroventral spines inclined at about $45^{\circ}$, basal 4-5 posteroventral spines strongly curved at base, almost decumbent, distal posteroventral spines inclined at about $30^{\circ}$.

Meso- and metathoracic legs cursorial. Femora without lobes and with very small anterior apical spine. Tibiae apically with two short spines and triangular extension. Distal part of femora, tibiae and tarsi covered with small black setae, organised in distal half of tibiae and on tarsi in a few rows. Middle basitarsus 1.5 times 


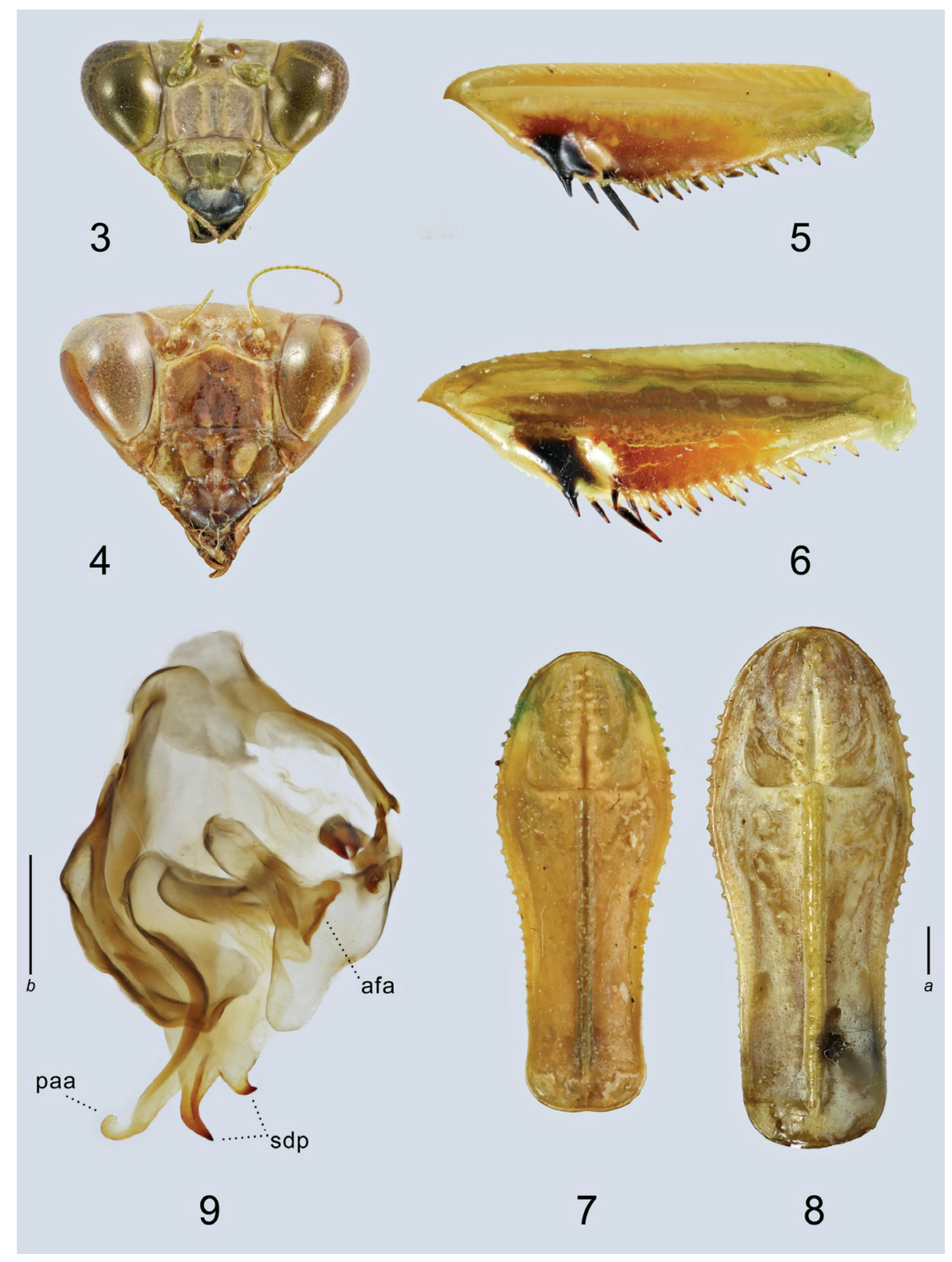

Figs 3-9. Dracomantis mirofraternus gen. et sp. n., details of morphology. 3, 5, 7, 9 holotype male; 4, 6, 8 - paratype female; 3, 4- head, frontal view; 5, 6 - forefemur, anterior view; 7, 8 - pronotum, dorsal view; 9 - male genitalia, dorsal view. Scales $1 \mathrm{~mm}$, a - for figs $3-8, b-$ for fig 9 . 
shorter than other tarsomeres combined; hind basitarsus very slightly longer than other tarsomeres combined.

Both pairs of wings fully developed, surpassing end of abdomen. Tegmen with widely parabolic apex, its length 3.7-3.9 times its maximum width distad of $\mathrm{CuP}$ termination. Costal field rapidly expands in the first third of tegmen, then gradually narrows, not reaching the apex, for the most part covered by long transverse veins slightly inclined distad with dense dentritic venules in-between them, especially irregular basally, more transverse and regular distally. Stigma extremely elongated and narrow, almost indistinct. Wing shorter than tegmen, elongated-triangular, with parabolic apex, twice longer its maximum width.

Abdomen dorsoventrally depressed, with eight visible rectangular coxosternites (II-IX), progressively shortening posteriorly. Coxosternite IX elongated, roughtly lancet shaped, slightly asymmetrical, apically densely covered by long setae, with two short styli and semi-circular notch between their bases. Tergite X strongly transverse, with widely rounded apex. Cerci circular in cross section, with 12 readily recognizable cercomeres, covered by long setae, first cercomere consists of 3 only partially separated cercomeres, last cercomere longer than penultimate one, but narrower than any of the others.

Genitalia (Fig. 9). Ventral phallomere elongated, rhomboidal. Sclerite L4A strongly sclerotized in its left half, significantly less so in its right, with the boundary between these areas quite clear, dividing ventral phallomere in two halves. Apex of ventral phallomere with two distal processes sdp, left one long and slightly curved, right one much smaller, short, curved and directed to the right. Both processes share common dorsal sclerotization at base. Sclerite L4B curved, of complex shape, widened distally. Sclerite L2 wide anteriorly, roughly triangular, with mostly diffused right border. Apical process paa long, directed leftside, with curved apex. Articulations A2 and A4 well developed. Left part of sclerite L1A wide, curved ventro-dorsad (so that its convexity directed posteriad) and widely curved anteriad along its longer dimension; right part more or less flat, wide, connected anteriorly though weakly sclerotized and dorso-ventrally curved part to sclerite L2. Sclerite L1 sclerotizes phalloid apophysis afa. Afa with longitudinal wrinkles, otherwise smooth, with two very short, barely separated processes, posterior process sometimes absent. Anterior process bean-shaped with rounded apex. Membranous lobe loa smaller than or comparable in size to the anterior afa process. Main lobe fda of the right phallomere sclerotized dorsally by sclerite R1A. Sclerite R3 very wide at its anterior end, rounded, sharply narrowing posteriorly. Apodeme pae generally weakly developed or absent. Sclerite R1B sclerotizes pia; the latter short, the sclerotized part is transverse, with weak creases. Process pva sclerotized by R1D, sharply curved, apex finger-shaped, narrowly rounded, with very weak creases.

Colouration. General colour green in life. Labrum black. Antenna brown past the most basal 10-15 antennomeres. Ocelli yellowish-green. Anterior face of forefemur basally with black spot resembling human molar in shape: basal "root" flush with black first discoidal spine and its socket, distal "root" extending along tibial 
spur groove in the direction of third discoidal spine but not reaching it or second discoidal spine, basal edge not reaching femur-trochanter connection, distal edge limited by tibial spur groove and dorsal edge not as clear, but barely exceeding a third of forefemur height. Area adjacent to this spot, dorsad and distad of it, approximately from half the maximum forefemur height, along anteroventral spines until femoral brush yellowish, in holotype male and sole female reddish, which may be an artifact of preservation or a natural variation. First to third discoidal spines and first anteroventral spine black on the anterior side, rest of femoral and tibial spines with brown apex only, with the first and the larger forefemoral anteroventral spines being darker than the rest or even black in some specimens. Forebasitarsus anteriorly with wide black longitudinal band starting from second third, rest of tarsomeres with black distal halves. Metazonal medial keel deep brown. Tegmen hyaline, transparent, except opaque green costal field, and narrow part of the rest of tegmina adjacent to it. Stigma light-green, very inconspicuous. Wing transparent, hyaline, except for greenish median part of costal field. Veins green to turquoise. Preserved specimens experience discoloration, especially metazonal keel and lighter-than-black spots.

Female (Fig. 2) similar to male (body length $36 \mathrm{~mm}$ ), with following differences.

Head (Fig. 4) 1.3 times wider than long, 1.5 times wider than supracoxal dilatation. Clypeus with a medial low and longitudinally elongated tubercle. Lower frons 1.3 times wider than high, distinctly pentagonal, flatter overall, its paramedian carinae even more flattened in medial part, but more pronounced in ventralmost part as two tubercles. Ocelli much smaller but raised above surrounding surface. Paramedian depressions on vertex more level with surrounding surface. Antennae significantly shorter than head length; antennomeres in the middle being the longest and ultimate antennomeres very flattened. Posterior line of head straight.

Tubercles on forecoxal dorsal (11-13), anterodorsal (19-21) and posterior edges (24) more prominent, continuing in distal halfs of the corresponding edges, while tubercles on ventral edge somewhat less prominent than in male. Lamellar dorsal part of forefemur (Fig. 6) more developed, with dorsal edge itself crenulated. Hind basitarsus noticeably longer than other tarsomeres combined.

Wings shortened compared to the male, merely reaching the apex of abdomen. Costal field of tegmen extremely wide for most of its length, about $1 / 3$ of the tegmen's length, weakly arcuate.

Abdomen oval, with six visible coxosternites (II-VII). Coxosternite VII smooth except apical lobes that densely covered by setae.

Colouration as in the male, but tegmen with green stripes along the main veins.

Measurements in $\mathrm{mm}$ are listed in Tables 1,2.

DISTRIBUTION. Current material indicates that the species inhabits the Central Highlands of Vietnam, with most findings concentrated on Kon Tum plateau (Fig. 10).

ETYMOLOGY. The species name is formed after Latin "mirus" (astonishing) and "frater" (brother), referring to the unexpected similarity of the male genitalia morphology with the genus Chlorocalis Stiewe, Shcherbakov et Vermeersch, 2019. 
Table 1. Individual measurements of Dracomantis mirofraternus gen. et sp. n.

\begin{tabular}{c|c|c|c|c|c|c|c|c|c|c}
\hline Specimen & Sex & T & H & P & M & D & N & FC & FF & FT \\
\hline ESZI001* & M & 38 & 5.7 & 9.7 & 6.8 & 3.8 & 2.5 & 7.9 & 9.1 & 6.5 \\
\hline F3459.23 & M & 46 & 5.7 & 10.3 & 7.1 & 3.9 & 2.7 & 7.8 & 9.9 & 6.7 \\
\hline F3459.24 & M & 44 & 5.8 & 10.4 & 6.9 & 4.2 & 2.5 & 8.2 & 9.7 & 6.9 \\
\hline $\mathrm{n}^{\circ}$ Mag. 3078 \#1 & M & 43 & 6.0 & 10.7 & 7.3 & 3.9 & 2.3 & 8.2 & 9.5 & 6.8 \\
\hline $\mathrm{n}^{\circ}$ Mag. 3078 \#2 & M & 49 & 6.2 & 11.0 & 7.8 & 4.1 & 2.6 & 8.7 & 10.8 & 7.0 \\
\hline $\mathrm{n}^{\circ}$ Mag. 3078 \#3 & M & 47 & 6.0 & 11.1 & 7.8 & 4.0 & 2.4 & 8.7 & 9.7 & 6.4 \\
\hline $\mathrm{n}^{\circ}$ Mag. 3078 \#4 & M & 45 & 5.3 & 9.5 & 6.7 & 3.8 & 2.5 & 8.3 & 9.8 & 6.2 \\
\hline ESPC0012 & M & 37 & 5.7 & 9.8 & 6.9 & 3.7 & 2.4 & 7.8 & 8.9 & 6.3 \\
\hline ESPC0013 & M & 37 & 5.6 & 10.2 & 7.2 & 3.7 & 2.5 & 7.9 & 9.5 & 6.4 \\
\hline ESZI002 & F & 36 & 6.6 & 11.0 & 7.7 & 4.3 & 3.1 & 9.3 & 10.4 & 7.0 \\
\hline
\end{tabular}

Legend: * - the holotype; $\mathrm{M}$ - male; $\mathrm{F}$ - female; $\mathrm{T}$ - total length from vertex to tip of abdomen; $\mathrm{H}$ - head maximum width; $\mathrm{P}$ - pronotum length; $\mathrm{M}$ - metazona length; $\mathrm{D}$ - pronotum maximum width; $\mathrm{N}$ - pronotum minimum width; $\mathrm{FC}$ - forecoxa length; $\mathrm{FF}$ - forefemur length; FT - foretibia length.

Table 2. Individual measurements (continued) and the number of femoral and tibial spines of Dracomantis mirofraternus gen. et sp. n.

\begin{tabular}{c|c|c|c|c|c|c|c|c|c|c}
\hline Specimen & Sex & FS & HF & HT & FW & CF & FP & FA & TP & TA \\
\hline ESZI001* & M & 6.3 & 9.0 & 9.3 & 35.5 & 3.0 & $5 / 5$ & $14 / 15$ & $13 / 13$ & $13 / 13$ \\
\hline F3459.23 & M & 6.3 & 10.4 & 9.7 & 34.0 & 2.9 & $5 / 5$ & $15 / 15$ & $12 / 13$ & $13 / 14$ \\
\hline F3459.24 & M & 6.4 & 10.2 & 9.4 & - & 3 & $5 / 5$ & $15 / 15$ & $12 / 13$ & $14 / 14$ \\
\hline $\mathrm{n}^{\circ}$ Mag. 3078 \#1 & M & 6.7 & 10.0 & 9.6 & - & 2.7 & $5 / 5$ & $15 / 15$ & $13 / 13$ & $11 / 11$ \\
\hline $\mathrm{n}^{\circ}$ Mag. 3078 \#2 & M & 6.6 & 10.5 & 8.7 & 35.8 & 3.4 & $4 / 5$ & $15 /-$ & $14 / 13$ & $14 /-$ \\
\hline $\mathrm{n}^{\circ}$ Mag. 3078 \#3 & M & 6.3 & 11.0 & 9.8 & 35.8 & 3.0 & $5 / 5$ & $15 / 15$ & $14 / 14$ & $13 / 13$ \\
\hline $\mathrm{n}^{\circ}$ Mag. 3078 \#4 & M & 6.2 & 10.0 & 9.9 & 33.7 & 3.1 & $5 / 5$ & $14 / 14$ & $14 / 14$ & $13 / 13$ \\
\hline ESPC0012 & M & 6.1 & - & - & 34.0 & 2.5 & $4 / 4$ & $15 / 15$ & $13 / 13$ & $14 / 14$ \\
\hline ESPC0013 & M & 6.1 & - & - & 33.5 & - & $4 / 4$ & $15 / 15$ & $14 / 16$ & $15 / 13$ \\
\hline ESZI002 & F & 6.7 & 9.4 & 9.9 & 23.5 & 3.4 & $5 / 5$ & $15 / 14$ & $14 / 14$ & $12 / 12$ \\
\hline
\end{tabular}

Legend: * - the holotype; M - male; F - female; FS - foretarsus length; HF - hind femur length; HT - hind tibia length; FW - forewing length; CF - costal field maximum width; FP - number of forefemoral posteroventral spines; FA - number of forefemoral anteroventral spines; TP - number of foretibial posteroventral spines; TA - number of foretibial anteroventral spines.

\section{DISCUSSION}

Dracomantis mirofraternus gen. et sp. $\mathrm{n}$. is yet another new piece in the puzzle of the Greater Mekong insect fauna. This is the fifth genus of Mantodea described from Vietnam during only the past three years, which was newly encountered and not erected for previously known species, indicating both a high diversity and our still very poor knowledge of praying mantises in this area. From morphological perspective, the taxon is interesting in variability in the number of forefemoral posteroventral spines, with some specimens possessing five, some four and a single 
specimen with different number of posteroventral spines on its left and right legs. This is a highly unusual trait, as the number of posteroventral spines on the forefemur is a very stable character among Mantodea families (Schwarz \& Roy, 2019). Mantidae, including Hierodulinae, are characterized by having four posteroventral spines, with a single previously known exception, Mekongomantis quinquespinosa Schwarz, Ehrmann et Shcherbakov, 2018, which, coincidentally, belongs to the same subfamily and was also described from Vietnam just two years earlier. Most surprisingly, Dracomantis gen. $\mathrm{n}$. shows a remarkable resemblance in the shape of male genitalia with another recently described sympatric genus Chlorocalis (Vermeersch et al., 2019). This similarity is all the more remarkable since both genera are complete opposites in terms of external morphology. The phylogenetic relationship between the two genera is currently under study.

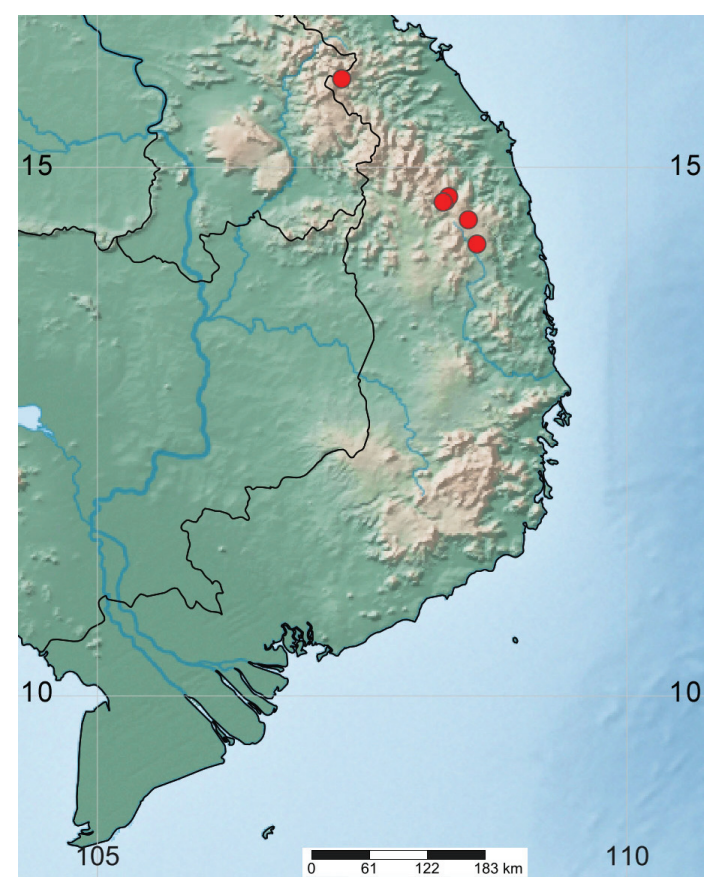

Fig. 10. Distribution of Dracomantis mirofraternus gen. et sp. n. in Vietnam.

The co-occurrence of Dracomantis mirofraternus gen. et sp. n. and Chlorocalis prasina Vermeersch, Shcherbakov et Stiewe, 2019 also raises the question of conservation status. C. prasina was evaluated as vulnerable (VU) according to the IUCR Red List assessment criteria (Vermeersch et al., 2019). D. mirofraternus gen. et sp. n. likely shares this status as known distribution and habitat preferences are a match between the two species. Nonetheless, more data is still needed to map the full distribution of the genus and confirm this hypothesis. It is astonishing that even today, as we are facing a global biodiversity crisis due to habitat loss and degradation, 
new taxa that remained so far undocumented and completely absent in older collection materials are still being discovered, not only on a species level, but also on a generic level, pointing out that our knowledge and understanding of biodiversity is still very incomplete.

\section{ACKNOWLEDGEMENTS}

The authors would like to express their sincere gratitude to Andrey Gorochov and Leonid Anisyutkin (ZIN) for the possibility to examine the collection of the institute, Luca Bartolozzi (University of Florence) and Dmitri Logunov (Manchester Museum) for the loan of specimens, Kris Anderson (USA) for fruitful discussions about the new taxon, Kirill Makarov (Moscow State Pedagogical University, Russia) for the macro setup used to make habitus photos, and RBINS researchers Wouter Dekoninck, Carl Vangestel and Gontran Sonnet for their support and making it possible to use the RBINS research infrastructures. We are also very thankful to the reviewers whose comments significantly improved the manuscript. ES's contribution was part of the research program of the M.V. Lomonosov Moscow State University, Project No. AAAA-A16-116021660095-7. This research received support from the SYNTHESYS+ project BE-TAF-1350 which is financed by the H2020 Research Infrastructures Programme.

\section{REFERENCES}

Brannoch, S.K., Wieland, F., Rivera, J., Klass, K.-D., Béthoux, O. \& Svenson, G.J. 2017. Manual of praying mantis morphology, nomenclature, and practices (Insecta, Mantodea). ZooKeys, 696: 1-100. DOI: https://doi.org/10.3897/zookeys.696.12542

Schwarz, C.J., Ehrmann, R. \& Shcherbakov, E. 2018. A new genus and species of praying mantis (Insecta, Mantodea, Mantidae) from Indochina, with a key to Mantidae of SouthEast Asia. Zootaxa, 4472(3): 581-593. DOI: https://doi.org/10.11646/zootaxa.4472.3.10

Schwarz, C.J. \& Roy, R. 2019. The systematics of Mantodea revisited: an updated classification incorporating multiple data sources (Insecta: Dictyoptera). Annales de la Société entomologique de France (N.S.), 55(2): 101-196. DOI: https://doi.org/10.1080/00379271. 2018.1556567

Shcherbakov, E. 2017. New genus and species of flower mantids (Insecta: Mantodea: Hymenopodidae) from Vietnam. Trudy Zoologicheskogo instituta RAN, 321(4): 411-424.

Shorthouse, D.P. 2010. SimpleMappr, an online tool to produce publication-quality point maps. Available from: http://www.simplemappr.net (accessed 18 May 2020)

Stiewe, M.B. \& Shcherbakov, E. 2017. Revision of the genera Nemotha Wood-Mason, 1884 and Tricondylomimus Chopard, 1930 stat. rev., with description of a new species (Dictyoptera: Mantodea). Annales de la Société entomologique de France (N.S.), 53(3): 175196. DOI: https://doi.org/10.1080/00379271.2017.1327330

Vermeersch, X.H.C. 2018a. Euchomenella adwinae sp. nov., a small stick mantis from southern Central Vietnam (Mantodea: Mantidae: Deroplatyinae: Euchomenellini). Belgian Journal of Entomology, 63: 1-9.

Vermeersch, X.H.C. 2018b. Phasmomantella gen. nov., a spectacular new genus of praying mantis from southern Central Vietnam (Mantodea, Mantidae, Deroplatyinae, Euchomene1lini). European Journal of Taxonomy, 442: 1-17. DOI: https://doi.org/10.5852/ejt.2018.442

Vermeersch, X.H.C., Stiewe, M.B.D. \& Shcherbakov, E.O. 2019. A new genus of praying mantis, Chlorocalis n. gen., with two new species from the Greater Mekong region (Mantodea: Mantidae). Annales de la Société entomologique de France (N.S.), 55(2): 197-210. DOI: https://doi.org/10.1080/00379271.2018.1562380 